\title{
Gözenekli Yapıya Sahip Kalça Protezi Tasarımı ve Uyluk Kemiği Üzerinde Sonlu Elemanlar Analizi
}

\author{
Hojjat GHAHRAMANZADEH ASL*D, Serap YILMAZ, Ertuğrul SARI
}

Erzincan Binali Yıldırım Üniversitesi, Mühendislik Fakültesi, Makine Mühendisliği Bölümü, Erzincan

Geliş / Received: 16/05/2018, Kabul / Accepted: 29/11/2018

\begin{abstract}
Öz
Uyluk kemiğinin yuvarlak başı (head of femur) kırıklarının tedavisinde, kalça protezi uygulanması sıklıkla kullanılmaktadır. Bununla birlikte, kullanılan protezlerin tasarımındaki farklılıklar, kullanılan malzeme özellikleri ve kemik hücrelerinin proteze bağlanması protezlerin biyomekanik davranışını büyük ölçüde etkilemektedir. Bu çalışmada, uyluk kemiği kırıklarında kullanılan gözenekli yapıya sahip kalça protezi tasarımı gerçekleştirilmiştir. Ayrıca kemiğin iyileşme haftalarına göre sergilediği özellikler de dikkate alınarak sonlu elemanlar yöntemiyle analizleri gerçekleştirilmiştir. Bu amaçla, iki parçadan oluşan kalça protezi, ayrıca iki farklı modelde ve üç farklı yoğunluğa sahip gözenekli yapılar SolidWorks 2018 yazılımı kullanılarak tasarlanmıştır. Kalça protezi malzemesi ve ayrıca farklı iyileşme periyotlarında oluşan kallus yapıların malzeme özellikleri de dikkate alınarak efektif elastisite modülü analizleri yapılmıştır. Daha sonra elde edilen sonuçlara göre kalça protezi uyluk kemiğine monte edilmiştir. Elde edilen modeller, 1000N'luk eksenel kuvvet altında ANSYS 18.0 yazılımı kullanılarak analiz edilmiştir. Gerçekleştirilen analizler sonucunda; kalça protezinde gözenekli yapılar kullanıldığından, yapılarda oluşan gerilmelerin daha düşük değerlerde olduğu tespit edilmiştir. Ayrıca kallus yapısının mekanik özelliklerindeki değişimin, kemik-protez yapısı üzerindeki etkiler bakımından önemli parametre olduğu sonucuna varılmıştır.
\end{abstract}

Anahtar Kelimeler: Gözenekli yapı, Kalça Protezi, Sonlu Elemanlar Analizi, Gerilme

\section{Design of Hip Prosthesis with Porous Structure and Finite Element Analysis on Femur Bone}

\begin{abstract}
Hip prosthesis is frequently used in the treatment of femoral head fractures. Material properties and the prosthetic attachment of the bone cells greatly influence the biomechanical behavior of the prosthesis because of differences in the design of the prosthesis. In this study, the design of the hip prosthesis used in femoral bone fractures was carried out in a different porous structure. In addition, finite element analyses were performed taking into account the mechanical properties of the bone according to the healing weeks. For this purpose, a two-piece hip prosthesis was designed. Lower part of prosthesis was modeled with two different porous structures with three different dense using SolidWorks 2018 software. Effective elasticity modulus was calculated taking into consideration of the mechanical properties of the hip prosthesis material and the callus structures which were formed during different healing periods. Then, according to the results obtained, the hip prosthesis was mounted on the thigh bone. The obtained models were analyzed using ANSYS 18.0 software under axial force of $1000 \mathrm{~N}$. As a result of the analyzes; since porous structures were used in the hip prosthesis, lower stresses in the hip prosthesis were observed. Also, it was concluded that differences on callus structure is an essential parameter that affects mechanical properties of bone-prosthesis structure.
\end{abstract}

Keywords: Porous Structure, Hip Prostheses, Finite Element Analyses, Stress

\section{Giriş}

İnsan vücudundaki en büyük yüklere maruz kalan kalça eklemi, uyluk kemiğinin yuvarlak başının, leğen kemiği ile birleşmesinden oluşmaktadır. Uyluk kemiği, yaşlanma neticesinde oluşan kemik erimesi, hastalıklar ve kaza sonucunda hasara uğramakta veya kırılmaktadır. Bu tür yaralanma ve hastalıklar sonucunda, hastanın hayatına devam 
edebilmesi ve yaşam kalitesini arttırmak için çeşitli kalça protezi uygulamaları geliştirilmiştir. Kalça protezleri farklı geometrilerde ve boyutlarda, büyük yükler taşıdıklarından dolayı, dayanımı yüksek ve biyouyumluluk özelliğine sahip olan Ti6A14V (Grade 5) malzemesinden üretilmektedir (Boyer, 1996; Ferrero, 2005). Bu protezler tek parça ve iki parça olarak hastanın vücut boyutlarına göre seçilip tedavisinde kullanılmaktadır. Literatürde kalça protezi analizleri için birçok çalışma mevcuttur. Canpolat (2010) yaptığı çalışmada kalça protezi için farklı geometriler geliştirmiş ve kalça protezlerini uyluk kemiğine monte ederek yük altında analizlerini gerçekleştirmiştir. Geliştirilen kalça protezi için yapılan analizler sonucunda, uyluk kemiğinde ve uyluk kemiği çimentosunda oluşan gerilmelerde düşüş olduğunu tespit etmiştir. Günümüzde yapılan çalışmalarda ise protezin kararlılığının sağlanmasının yanı sıra hastanın hareket özgürlüğü de göz önüne alınmaya başlanmıştır. Bunun sağlanması için protezde yüzey geliştirme işlemleri yapılmaktadır. Yüzey geliştirme işlemleri protez ve kemik arasındaki sürtünmeyi ve aşınmayı azaltmaya yönelik çalışmalardır (Bilgen, 2011). Milijkovic (2011)'e göre kalça protezi için en önemli unsur protezin iyi bir şekilde konumlandırılmış olmasıdır. Kayabaşı (2011)'nın çalışmasında, kalça protezi sapında kanal açarak, kalça protezinin uyluk kemiğine ve kemik çimentosuna uyguladığı gerilmeleri azaltmak hedeflenmiştir. Sonuç olarak açılan kanal protez ve kemiğin temas alanının artması sonucunda uyluk kemiğinde oluşan gerilmelerde düşüş görülmüştür. Ayrıca protezin kemiğe daha iyi bir şekilde bağlandığ 1 tespit edilmiştir. Son yıllarda implant malzemelerinin gözenekli yapılardan üretiminin geometrik, mekanik ve biyolojik özelliklerinden dolayı arttığı görülmektedir (Güden ve Yıldırım, 2015). Özellikle implant malzemesi olarak kullanılan Ti6A14V alaşımının homojen gözenek boyutuna ve yüksek gözenek yüzde miktarları ile üretildiğinde elastisite modülünün kemiğe daha yakın olacağı bilinmektedir. Gözenekli yapıların asıl kullanım amac1, kemiksi dokuların gelişimini teşvik etmektir (Güden ve Y1ldırım, 2015; Bram vd., 2001; Wen vd., 2001; Wen vd., 2002). Ortopedik implantlar da, $150 \mu \mathrm{m}$ ile $500 \mu \mathrm{m}$ arasındaki gözenekler içerisinde kemik hücrelerinin gelişimine izin vererek implanların kemiğe bağlanmasını sağlamaktadır (Güden ve Yıldırım 2015). Kullanılan implant malzemelerinin elastisite modüllerinin kemiğe yakın olması her zaman istenilen bir durumdur (Balazic vd., 2007). Literatürde farklı malzemeler için gözenekli yapılar tasarlanmış ve efektif elastisite modülleri hesaplanmıştır (Luo vd., 2016; Naghieh vd., 2016; Entezari vd., 2016; Wang vd., 2017). Ali ve Şen (2017) çalışmalarında farklı geometrilere sahip gözenekli yapılar tasarlamışlar ve bası kuvveti altında efektif elastisite modüllerini hesaplamışlardır. Sonuç olarak gözenekli yapılarda yoğunluk miktarı azaldıkça, elastisite modülünün de azaldığını tespit etmişlerdir. Başka bir çalışmada uyluk kemiğinde kullanılmak üzere 14 farklı titanyum gözenekli yapı oluşturularak biyomekanik yükleme altındaki davranışları incelenmiştir. Yoğunluk oranları \%64, 73, 76 ve 81 olarak belirlenirken gözenekli yapının içi $\% 11,22,27,34,40$ ve 50 oranlarında boşaltılmıştır. Gözenek boyutları ise $0.8,1.1$, 1.5 ve $1.8 \mathrm{~mm}$ olarak belirlenmiştir. Çalışma sonucunda gözenekli yapının yoğunluğunun artırılmasının içinin boşaltılmasından daha iyi sonuç verdiğini vurgulamışlardır (Wieding vd., 2013). Bu çalışmada iki parçadan oluşan kalça protezi tasarımı ve analizi hedeflenmiştir. Ayrıca yapılan analizlerde iki farklı geometriye ve üç farklı yoğunluğa sahip gözenekli yapıların efektif elastisite modülleri hesaplanarak kalça protezinde kullanılması için tasarlanmış ve analiz edilmiş modeller arasında en iyi malzeme yoğunluğu tespit edilmiştir. $\mathrm{Bu}$ amaçla gözenekli yapılar ve kalça protezi modeli SolidWorks 2018 yazılımı kullanılarak tasarlanmıştır. 
Gözenekli yapıların ve kemik iyileşme süresine göre değişen efektif elastisite modülünün belirlenmesi, ayrıca kalça protezinin gerilme analizleri için ANSYS Workbench 18 yazılımı kullanılmıştır. Sonuçta tasarlanmış olan gözenekli yapıya sahip kalça protezi, dolu metalden yapılan kalça protezine göre uyluk kemiğinde daha az gerilme oluşturmuştur. Ayrıca kalça protezinde oluşan gerilmelerde de düşüş tespit edilmiştir. Gözenekli yapılara sahip malzemeler ile üretilen kalça protezleri kemiğe tutunma açısından avantajlı olduğu düşünülmektedir. Ayrıca protezde ve kemikte oluşan gerilme miktarlarının azalmasına sebep olduğu açısından avantajlı oldukları görülmüştür.

\section{Materyal ve Metot}

\subsection{Kalça Protezi Tasarımı}

Çalışmada planlanan kalça protezi tasarımı SolidWorks 2018 yazılımı kullanılarak gerçekleştirilmiştir. Kalça protezinin iki parçadan oluşturmasının sebebi, farklı kalça protezi boyutlarının protez sap1 boyutunu değiştirerek ayarlanabilmesidir. $\mathrm{Bu}$ sebepten dolayı çalışmamızda iki parçadan oluşan kalça protezi tasarlanmıştır. Tasarlanmış olan kalça protezi Şekil 1'de verilmiştir.

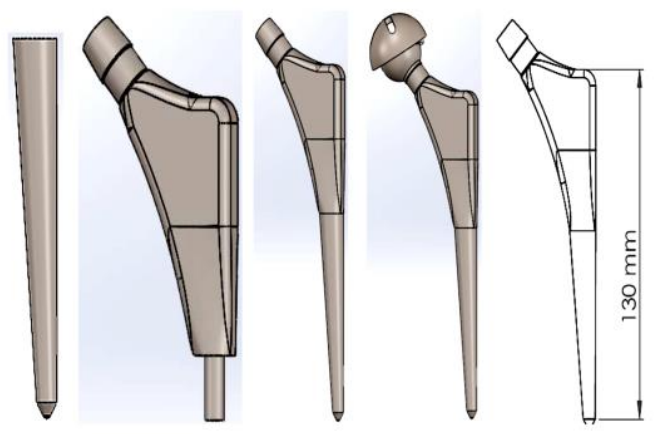

Şekil 1. Tasarlanmış olan kalça protezi.

\subsection{Gözenekli Yapı Tasarımı}

Kalça protezinin kemiğe daha iyi tutunabilmesi için protezin alt parçasının gözenekli yapıdan tasarlanması ve analiz edilmesi düşünülmüştür (Giró-Perafita et al. (2016)). Bu bağlamda tasarlanmış modeller içerisinde optimum gözenekli yapı yoğunluğunu belirlemek için 2 farkl1 geometriye ve üç farklı yoğunluğa sahip gözenekli yapı tasarlanmıştır. Bunun amacı geometrinin ve tasarlanan gözenekli yapının yoğunluğunun modeldeki efektif elastisite modülüne etkisini incelemektir. Tasarımda kullanılan modeller literatürde sıklıkla kullanılmakta olan modeller arasından seçilerek tasarlanmıştır (Wieding et al. (2013), Entezari et al. (2016), Naghieh et al (2016)). Birinci modelde yap1 içerisinde herhangi bir boşluğun olmadığı ve gözenekler oluşturularak boşluklar meydana getirilmiştir. Böylece yapının yoğunluğu az miktarda düşürülmüştür. İkinci modelde parçanın yoğunluğunu daha fazla düşürmek amaciyla her yönden prizmatik boşluklar oluşturulmuş ayrıca silindirik boşluklarla farklı yoğunluklarda yapı elde edilmiştir. Böylece daha fazla boşluk oluşturulmuş ve gözenek miktarının artması sağlanmıştır. Analizlerden elde edilen efektif elastisite modülü hesabı kemik iyileşme süresine göre gerçekleştirilerek, kalça protezi analizleri yapılmıştır. Tasarlanmış olan modeller Şekil 2'de, ayrıca tasarlanmış olan modellerin yoğunlukları Tablo 1'de verilmiştir.

Tablo 1. Tasarlanmış olan gözenekli yapıların yoğunluk değerleri.

\begin{tabular}{ccc}
\hline & Hacim $\left(\mathbf{m m}^{\mathbf{3}}\right)$ & Yoğunluğu (\%) \\
\hline Küp & 1,728 & 100 \\
\hline Model 1-35 & 0,48 & 27,77 \\
$\boldsymbol{\mu} \mathbf{m}$ & & \\
\hline $\begin{array}{c}\text { Model 1-70 } \\
\boldsymbol{\mu m}\end{array}$ & 0,4 & 23,148 \\
\hline Model 1-105 & 0,25 & \\
$\boldsymbol{\mu m}$ & & \\
\hline Model 2-35 & 1,62 & 93,767 \\
$\boldsymbol{\mu m}$ & & \\
\hline Model 2-70 & 1,35 & \\
$\boldsymbol{\mu m}$ & & \\
\hline
\end{tabular}




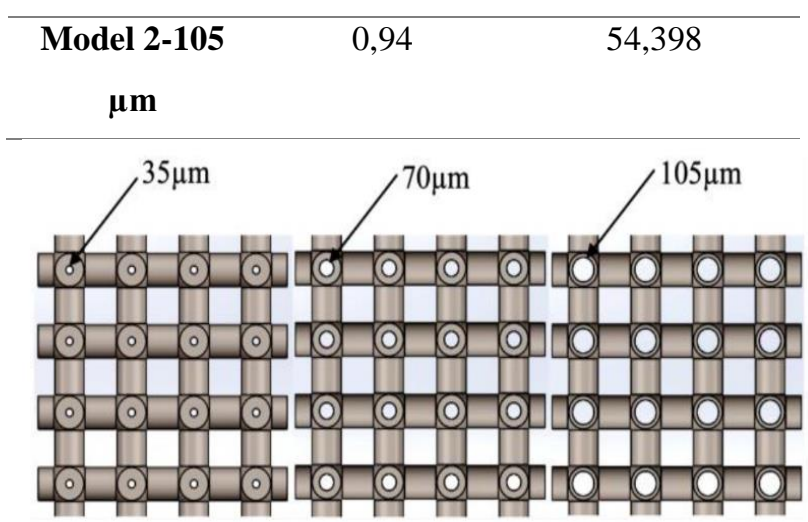

(a)

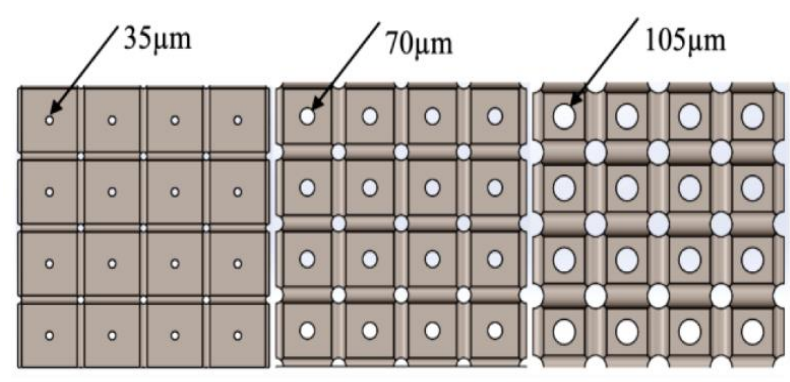

(b)

Şekil 2. Tasarlanmış olan gözenekli yapılar, model 1 (a), model 2 (b).

\subsection{Efektif Elastisite Modülü Hesaplanması}

Çalışmada Ti6Al4V malzemesinin kullanılmıştır. Bu kapsamda tasarlanmış olan gözenekli yapılar bası yüküne maruz bırakılarak şekil değiştirme miktarları elde edilmiştir. Ayrıca, kemiklerin gelişmesinden dolayı gözenekli yapıların içerisinde büyümüş olan kemik hücrelerinin etkileri de göz önünde bulundurularak $0,1,8$ ve 16 . haftadaki davranışlarına göre modeller hazırlanmıştır ve analizler gerçekleştirilmiştir. Gözenekli yapıların içerisinde bulunan boşluklar farklı bir parça olarak tasarlanmış ve gözenekli yapıların içerisine yerleşitirilmiştir. Haftalara göre bu parçaya farklı elastisite modülü ve poisson oranı tanımlanmış ve analizler gerçekleştirilmiştir. Protezler insan vücudunda elastik bölgede kaldıklarından, analizler gözenekli yapıların elastik bölgede şekil değiştirecekleri şekilde yapılmıştır. Elde edilen şekil değiştirme miktarları denklem 1'de yerleştirilerek her model için efektif elastisite modülleri hesaplanmıştır. Malzemenin ve Kallus yapiların haftalara göre malzeme özellikleri Tablo 2'de verilmiştir. Analizler Şekil 3'de verildiği gibi ANSYS Workbench 18.0 kullanılarak gerçekleştirilmiştir. Analizler $1 \mathrm{MPa}$ basınç altında, blokların alt tarafindan sabitlenmesi ile gerçekleştirilmiştir.
a) $\sigma=\mathrm{E}^{*} \varepsilon$
b) $\varepsilon=\frac{\Delta \mathrm{L}}{\mathrm{L} 0}$
c) $E=\frac{\sigma * \mathrm{LO}}{\Delta \mathrm{L}}$

\section{Denklem (1)}

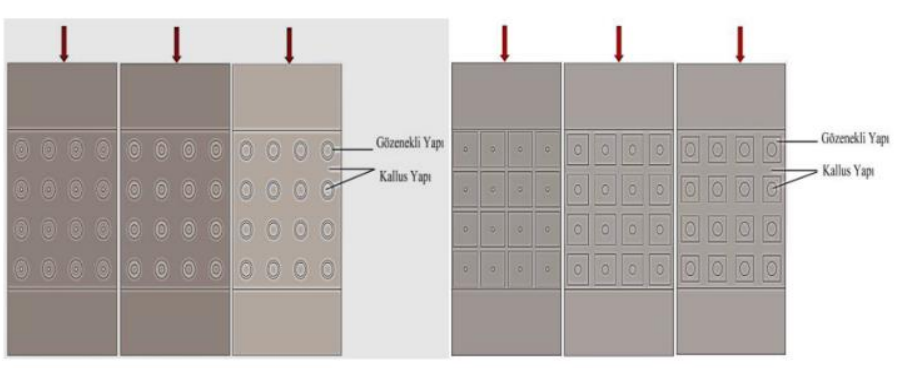

(a)

(b)

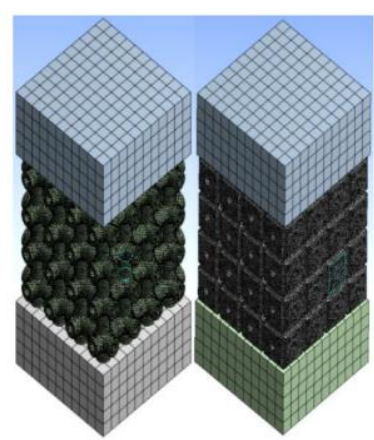

(c)

Şekil 3. Kallus yapıya sahip efektif elastisite modülü analizi, 1.Model (a), 2.Model (b), Mesh yapısı (c).

Tablo 2. Analizlerde kullanılan malzemelerin mekanik özellikleri.

\begin{tabular}{|lll}
\hline Malzeme/Model & $\begin{array}{l}\text { Elastisite } \\
\text { Modülü (MPa) }\end{array}$ & $\begin{array}{l}\text { Poisson } \\
\text { Oranı }\end{array}$ \\
\hline Ti6Al4V & 113800 & 0,34 \\
\hline Uyluk kemiği & 17000 & 0,3 \\
\hline 0 hafta-Kallus & 0 & 0 \\
\hline
\end{tabular}




\begin{tabular}{lcc}
\hline $\mathbf{1}$ hafta-Kallus & 0,00019 & 0,3 \\
\hline $\mathbf{8}$ hafta-Kallus & 28 & 0,3 \\
\hline $\mathbf{1 6}$ hafta-Kallus & 75 & 0,3
\end{tabular}

Ayrıca mesh yapısının 0,84 Element Quality değerine ve 0,22 Skewnees değerine sahiptir.

\subsection{Kalça Protezi Analizi}

Tasarlanmış olan iki parçadan oluşan kalça protezi uyluk kemiğine monte edilerek Sonlu Elemanlar Analizine tabi tutulmuştur. Kalça protezi yerleştirilmesinde Milijkovic et al. (2011) çalışması göz önünde bulundurarak standartlara uygun bir şekilde monte edilmiştir. Analizler ANSYS Workbench 18 yazılımı vasıtasıyla $1000 \mathrm{~N}$ yük altında gerçekleştirilmiştir. Modellerin oluşturulması için SolidWorks 2018 yazılımı kullanılmıştır. Analizler için kalça protezinin üst parçası yükün büyük bir kısmını taşıdığı için Ti6A14V alaşımı tanıtılmıştır. Kalça protezinin alt parçası için Ti6A14V ve gözenekli yapılardan elde edilen haftalık kemik iyileşme sürelerine göre efektif elastisite modülü tanıtılarak 25 farklı analiz gerçekleştirilmiştir. Uyluk kemiğinin diz eklemi ile birleştiği bölgeden sabitlenerek analizler gerçekleştirilmiştir. Analizler sonucunda, uyluk kemiğinde ve kalça protezinin her iki parçasında oluşan gerilmeler, ayrıca oluşan deplasman miktarları incelenmiştir. SolidWorks yazılımından elde edilen montaj model Şekil 4'de verilmiştir. ANSYS yazılımında oluşturulan mesh yapısı Şekil 4,b'de verilmiştir. Mesh yapısı toplam 61960 düğüm noktasına ve 41959 eleman sayısına sahiptir.
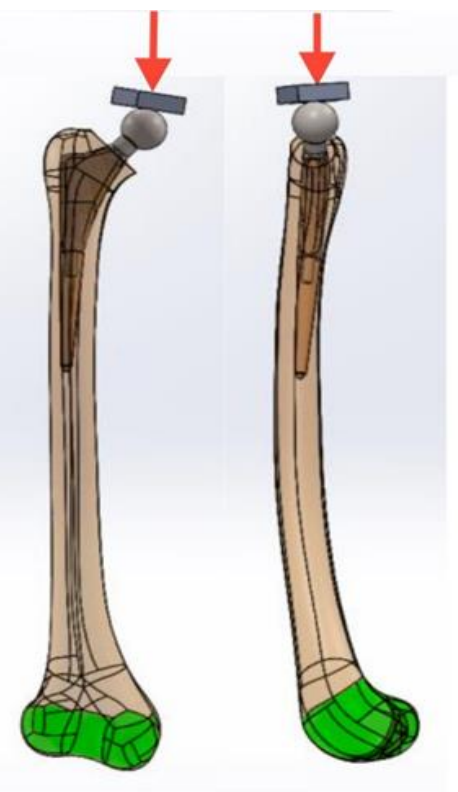

(a)

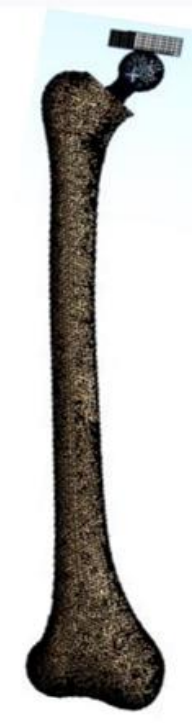

(b)

Şekil 4. Kalça protezinin uyluk kemiğine monte edilmiş görüntüsü (a), Mesh yapısı (b)

\section{Bulgular ve Tartışma}

\subsection{Efektif Elastisite Modülü Hesabı}

Gözenekli yapıların analizleri sonucundan elde edilen deplasman değerleri Tablo 3'te verilmiştir. Elde edilen deplasman değerlerine göre efektif elastisite modülleri denklem (1) kullanılarak $1 \mathrm{MPa}$ gerilme için hesaplanmıştır ve Şekil 5'de verilmiştir. Ayrıca sonlu elemanlar analizlerinden elde edilen deplasman değerleri Şekil 6'da gösterilmiştir.

Tablo 3. Analizlerden elde edilen deplasman değerleri

\begin{tabular}{lccccccc}
\hline \multicolumn{3}{c}{ 1. Model Deplasman Değerleri $(\mathbf{m m})$} & \multicolumn{3}{c}{ 2. Model Model Deplasman Değerleri (mm) } \\
\hline & $\mathbf{1 0 5}$ & $\mathbf{7 0}$ & $\mathbf{3 5}$ & & $\mathbf{1 0 5}$ & $\mathbf{7 0}$ & $\mathbf{3 5}$ \\
\hline 0. Hafta & $3.52 \mathrm{E}-08$ & $1.76 \mathrm{E}-08$ & $1.35 \mathrm{E}-08$ & $\mathbf{0 . ~ H a f t a}$ & $8.1 \mathrm{E}-09$ & $6.89 \mathrm{E}-09$ & $1.80 \mathrm{E}-09$ \\
\hline 1. Hafta & $3.49 \mathrm{E}-08$ & $1.74 \mathrm{E}-08$ & $1.33 \mathrm{E}-08$ & $\mathbf{1 . ~ H a f t a}$ & $4.29 \mathrm{E}-09$ & $2.41 \mathrm{E}-09$ & $1.79 \mathrm{E}-09$ \\
\hline 8. Hafta & $3.44 \mathrm{E}-08$ & $1.73 \mathrm{E}-08$ & $1.33 \mathrm{E}-08$ & $\mathbf{8 . ~ H a f t a}$ & $4.28 \mathrm{E}-09$ & $2.41 \mathrm{E}-09$ & $1.79 \mathrm{E}-09$ \\
\hline 16. Hafta & $3.37 \mathrm{E}-08$ & $1.71 \mathrm{E}-08$ & $1.32 \mathrm{E}-08$ & $\mathbf{1 6 . ~ H a f t a}$ & $4.27 \mathrm{E}-09$ & $2.41 \mathrm{E}-09$ & $1.79 \mathrm{E}-09$ \\
\hline
\end{tabular}




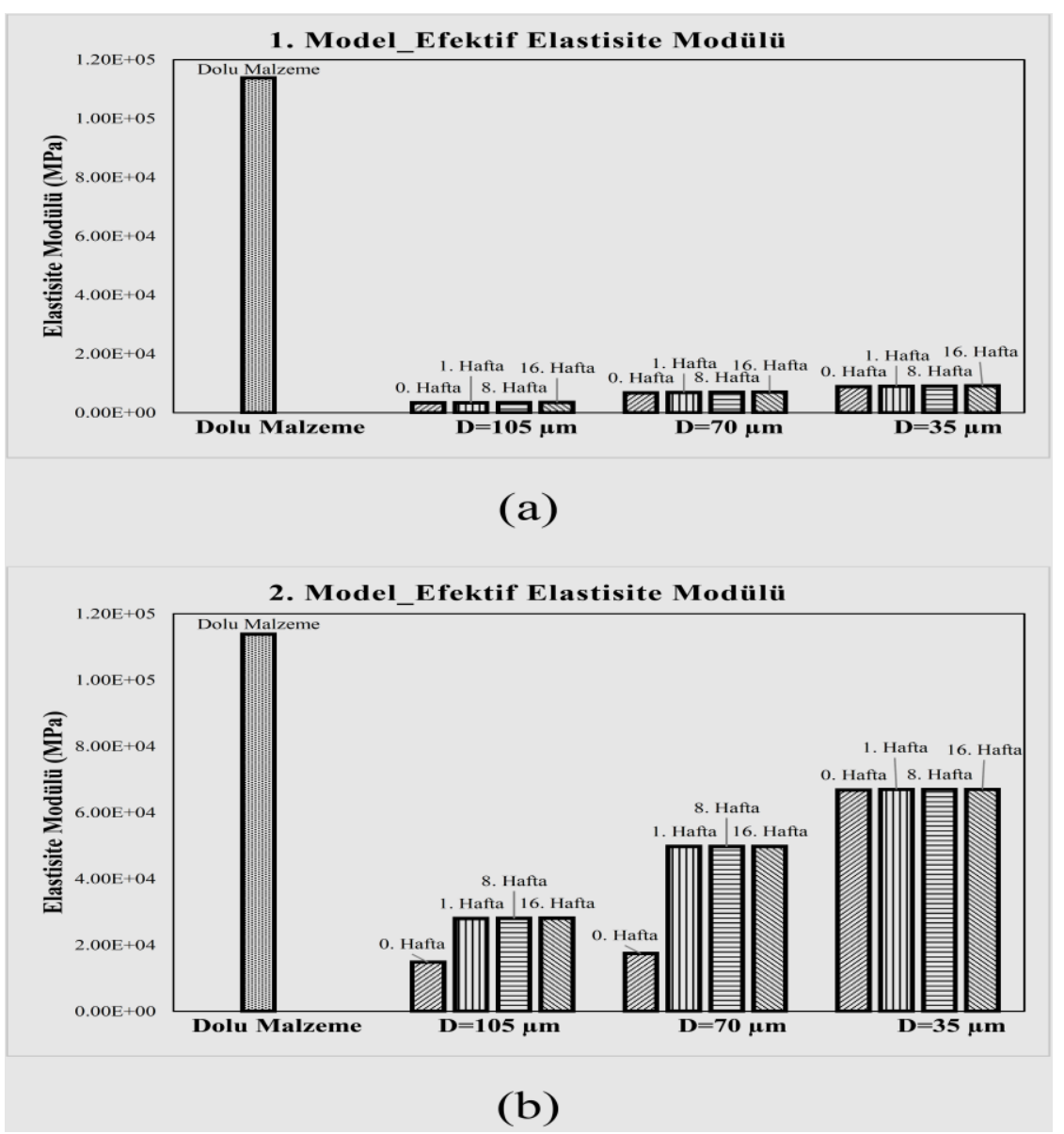

Şekil 5. Sonlu elemanlardan elde edilen efektif elastisite modülü, 1. Model (a), 2. Model (b)

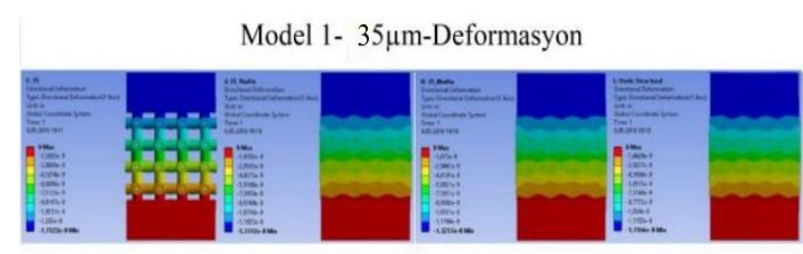

Model 1-70 $\mu \mathrm{m}$-Deformasyon

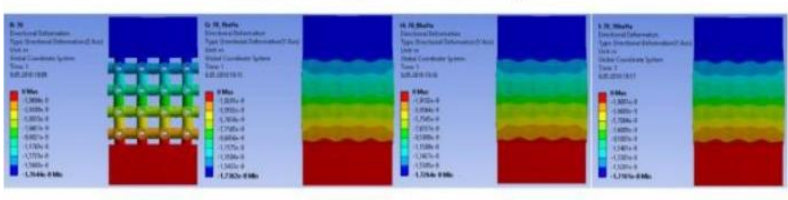

Model 1-105 $\mu$ m-Deformasyon

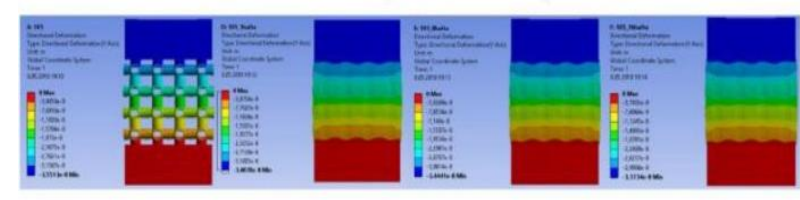

(a)

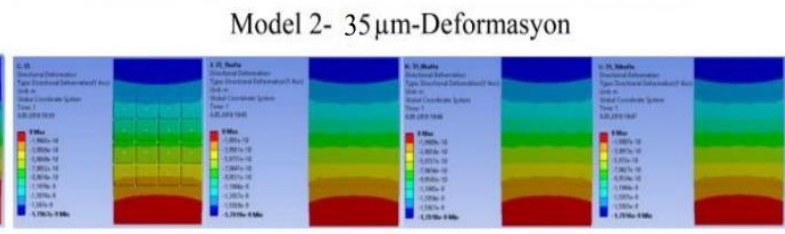

Model 2-70 $\mu \mathrm{m}$-Deformasyon

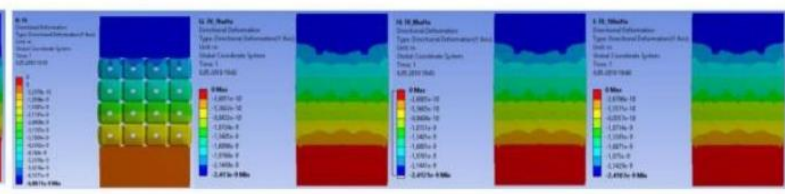

Model 2-105 $\mu \mathrm{m}$-Deformasyon

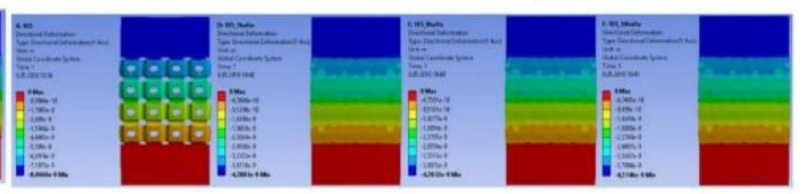

(b)

Şekil 6. Sonlu elemanlardan elde edilen deplasman değerleri, 1. Model (a), 2. Model (b).

Analizler farklı geometride ve farklı yoğunluklarda kemik iyileşme haftalarına göre incelenmiştir. Grafikler incelendiğinde gözeneksiz malzemeye göre gözenekli malzemelerin elastisite modüllerinde düşüş olduğu görülmektedir. Ayrıca modellerin yoğunlukları düştükçe (boşluk alanların artması) elastisite modülleride düşüş 
göstermiştir. Şekil 5.a. incelendiğinde tüm haftalar için yükün malzeme ve iyileşme sürecinde olan kemik tarafından taşındı ğ 1 görülmektedir. Çünkü haftalara göre efektif elastisite modülünde çok fazla değişim görülmemektedir. $\mathrm{Bu}$ modelde iyileşme sürecinde olan kemik yapıların elastisite modülleri farklı yoğunluklarda olan gözenekli yapılara çok yakın olduğunu göstermektedir. Şekil 5.b. incelendiğinde dolu malzemeye göre efektif elastisite modülünde bir düşüş görülmektedir. Her 3 yoğunluktaki model için 1. haftadan sonra efektif elastisite modülünde bir artış görülmektedir. $\mathrm{Bu}$ da 1 . haftadan sonra yükün hem kemik hem de parça tarafından taşındığını göstermektedir. Haftalar ilerledikçe kemik malzemesinin elastisite modüllerinde artış meydana gelmektedir ve bu durum birinci haftadan sonra 2. Modelde kendini göstermiştir. Fakat 1. haftadan sonra efektif elastisite modülünde 1. modelde olduğu gibi fazla bir değişim söz konusu olmamıştır. $\mathrm{Bu}$ da yükün iyileşme sürecinde olan kemik ve gözenekli yap1 tarafından taşındığıını göstermektedir.

\subsection{Kalça Protezi Analizi}

Vücut ağırlığı ortalama bir insanın ağırlığı düşünülerek $1000 \mathrm{~N}$ olarak alınmıştır. Kalça protezi analizi, uyluk kemiğine monte edilmiş model üzerinde $1000 \mathrm{~N}$ yük altında 25 farklı malzeme özelliğine göre gerçekleştirilmiştir. Analizden elde edilen resimler uyluk kemiğinde, kalça protezi üst parçasında ve alt parçasında oluşan gerilmeleri ve tüm modelde oluşan deplasman değerini göstermektedir (Şekil 7). Analizler dolu malzemeden ve farklı yoğunlukta ve farklı iyileşme sürecindeki kemik değerlerinden elde edilen efektif elastisite modüllerine göre gerçekleştirilmiş olup uyluk kemiğinde, kalça protezi üst parçasında ve alt parçasında oluşan gerilme değerleri ve tüm modelde oluşan deplasman değerleri Şekil 8'de grafik halinde verilmiştir.

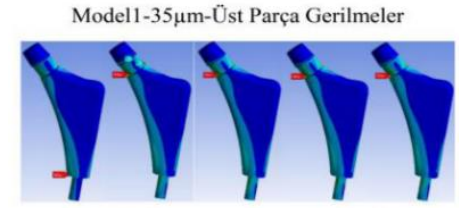

Model1-35 $\mu \mathrm{m}$-Alt Parça Gerilmeler

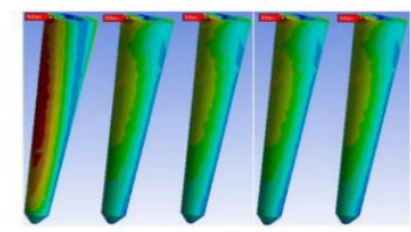

Model1-35 $\mu \mathrm{m}-$ Uyluk Kemiği Gerilmeler

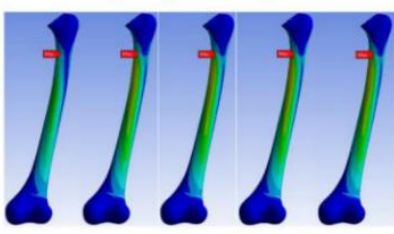

Model1-35 $\mu \mathrm{m}$-Toplam Deformasyon

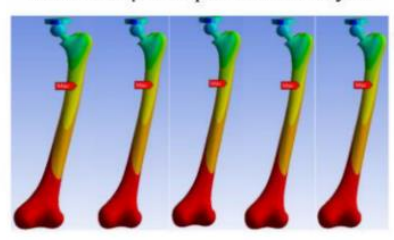

Model1-70 $\mu \mathrm{m}$-Üst Parça Gerilmeler

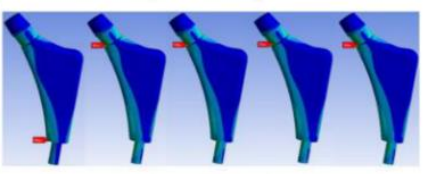

Model1-70 $\mu \mathrm{m}$-Alt Parça Gerilmeler

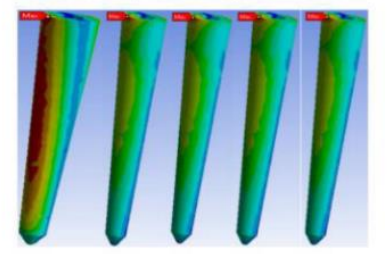

Model1-70 $\mu \mathrm{m}-$ Uyluk Kemiği Gerilmeler

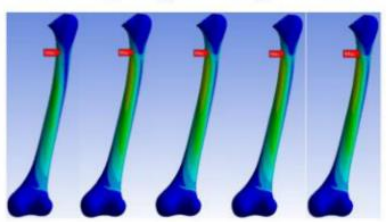

Model1-70 $\mu \mathrm{m}$-Toplam Deformasyon

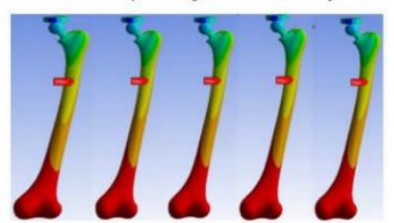

Model1-105um-Üst Parça Gerilmeler

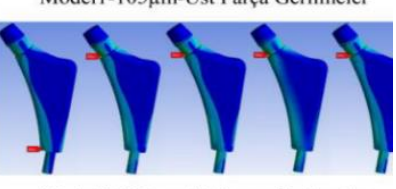

Model1-105 $\mu \mathrm{m}$-Alt Parça Gerilmeler

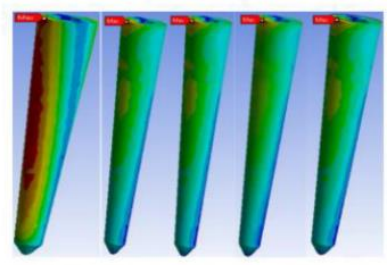

Model1-105 $\mu \mathrm{m}$-Uyluk Kemiği Gerilmeler

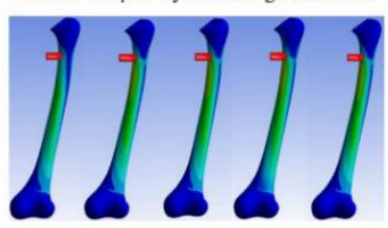

Model1-105 $\mu \mathrm{m}$-Toplam Deformasyon

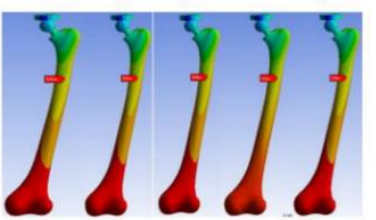

(a) 


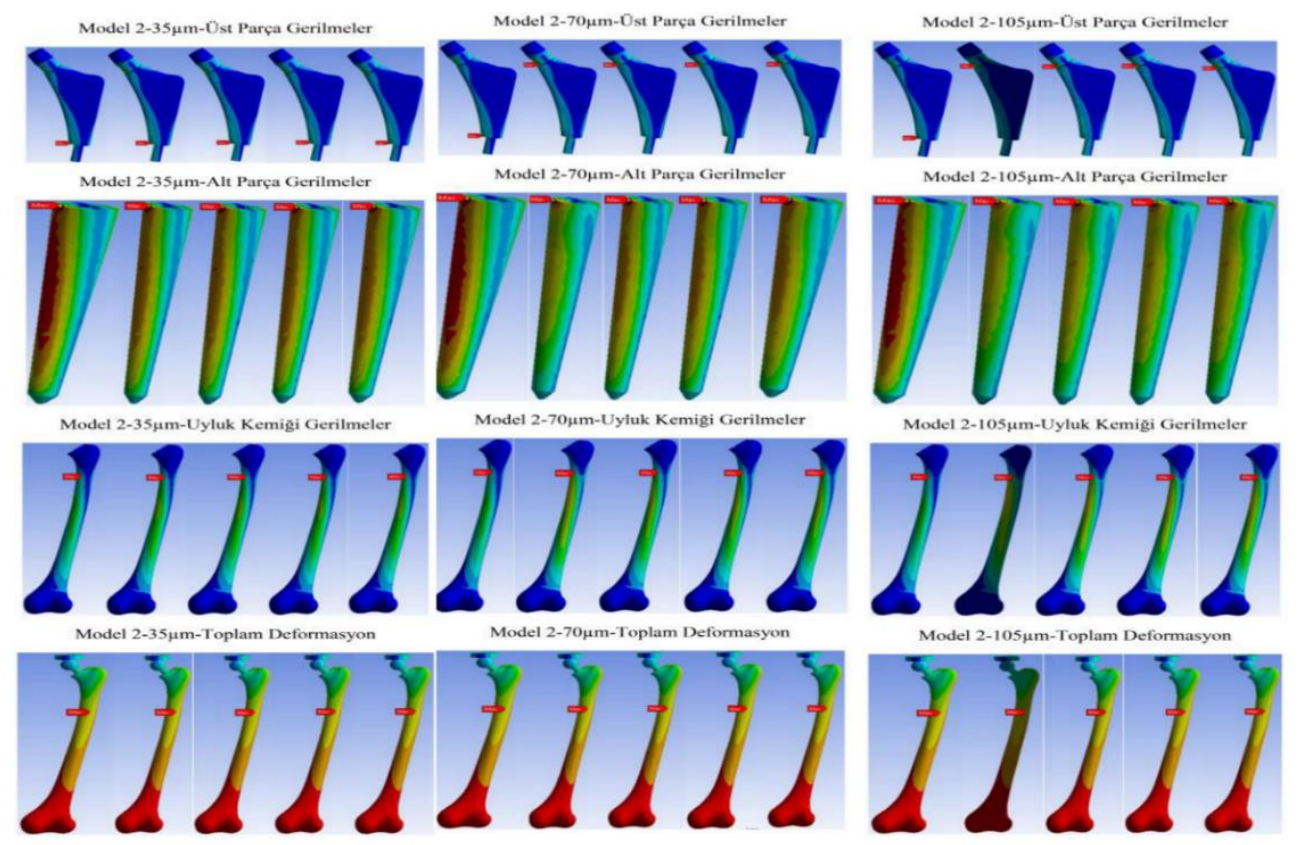

(b)

Şekil 7. Kalça protezi üst parçası, alt parçası ve uyluk kemiği oluşan gerileme ve tüm modelde oluşan deplasman analizleri, 1. Model (a), 2. Model (b)

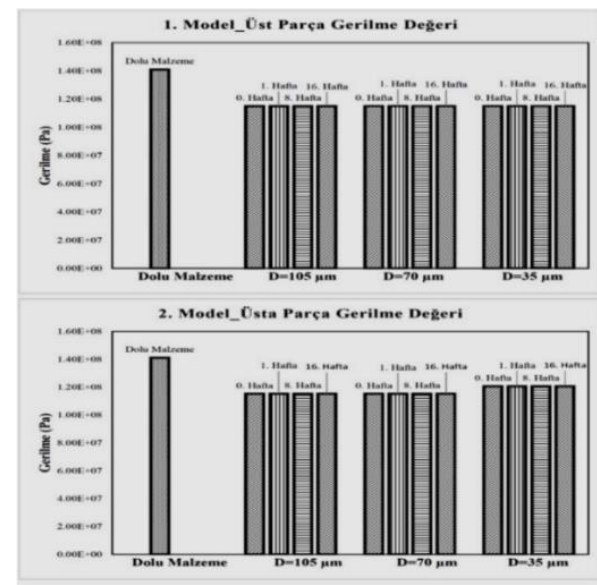

(a)

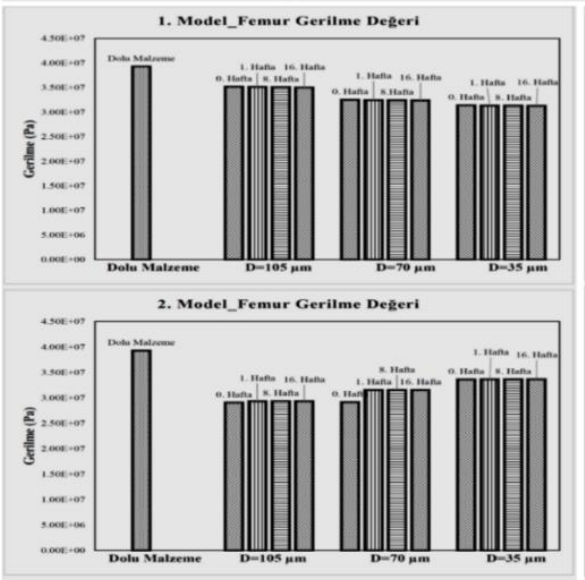

(c)

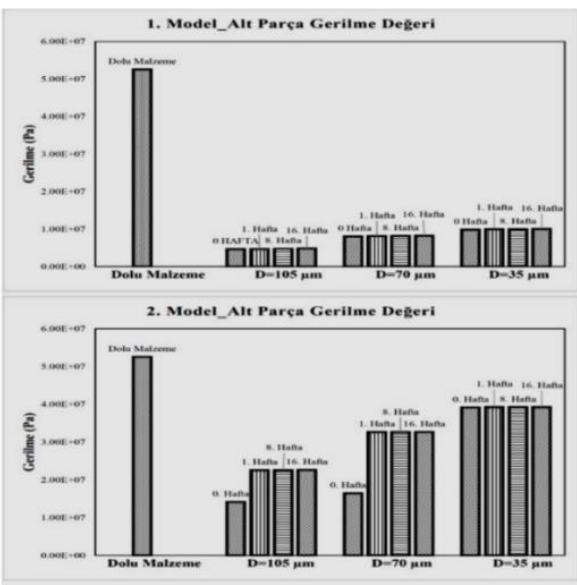

(b)

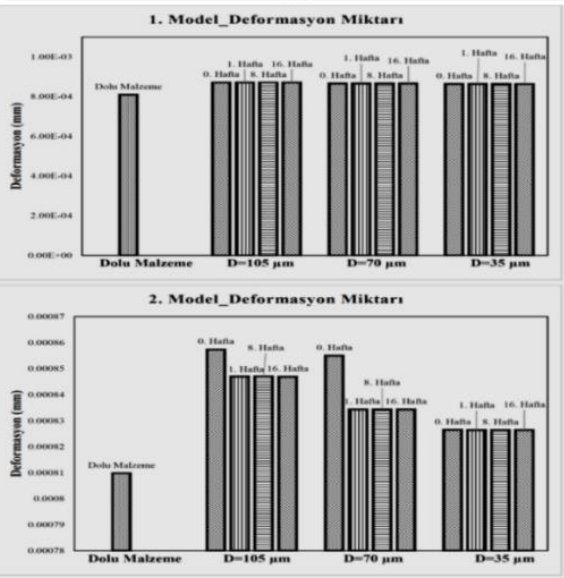

(d)

Şekil 8. Kalça protezi üst parça (a), Alt parça (b), Uyluk kemiği (c) gerilme ve Tüm model deplasman (d) değerleri. 
Şekil 8 (a) incelendiğinde, kalça protezi alt parçada gözenekli yapı kullanıldığında, kalça protezi üst parçasında dolu bir malzeme kullanıldığına göre oluşan gerilemelerde düşüş tespit edilmiştir. Dolu bir malzeme ile yapılan analizde oluşan gerilme değeri $\sim 140$ $\mathrm{MPa}$ iken, gözenekli yapı ile yapılan analizlerde bu değer $115 \mathrm{MPa}$ olarak elde edilmiştir. Sonuçlara göre, her iki modelde yaklaşık değerler elde edilmiştir. Şekil 8 (b) incelendiğinde, kalça protezi alt parçasında gözenekli yapı kullanıldığında dolu malzemeye göre daha düşük gerilmelere maruz kaldıkları tespit edilmiştir. Dolu malzeme ile yapılan analizde oluşan gerilme değeri $\sim 52 \mathrm{MPa}$ elde edilmiştir. Gözenekli yap1 ile yapilan analizlerde birinci modelde yoğunluğa göre gerilme değerleri sirasıyla 4,7, 8,13 ve 9,93 MPa olarak elde edilmiştir. Gerilme değerleri ikinci modelde malzeme yoğunluğuna göre 22,6, 32,7 ve 39,2 $\mathrm{MPa}$ şekilde değişmiştir. Sonuçlara bakıldığında, malzemedeki yoğunluk miktarı (doluluk oranı) arttıkça oluşan gerilmelerde de bir artış görülmektedir. Bunun sebebi ise parçadaki doluluk oranı arttıkça parça daha az elastik şekil değişimine uğramakta ve bu da gerilme değerlerinin artmasına sebebiyet vermektedir. Şekil 8 (c) incelendiğinde, gözenekli yapılar kullanıldığında dolu malzeme kullanıldığına göre uyluk kemiğinde oluşan gerilmeler de bir düşüş görülmektedir. Gerilme değerleri dolu malzeme kullanıldığı zaman $~ 39 \mathrm{MPa}$ iken gözenekli yapılarda bu değer daha düşüktür. Bunun sebebi ise, gözenekli yapılar yük altında az miktarda da olsa bir elastik şekil değişimine uğramaktadırlar ve dolayısıyla yükün bir kısmını absorbe ederek uyluk kemiğine daha düşük bir yük iletmektedirler. $\mathrm{Bu}$ da uyluk kemiğinde daha düşük gerilmelerin oluşumunu sağlamaktadır. Ayrıca gözenekli yapıların doluluk oranları arttıkça gerilmelerde de bir artış görülmektedir. Yoğunluk oranı arttıkça kalça protezinde daha az elastik şekil değişimi oluşmakta ve böylece yükün daha büyük bir kısmı uyluk kemiği tarafından taşınmaktadır.
Şekil 8 (d) incelendiğinde uyluk kemiği-kalça protezi sisteminde oluşan toplam deformasyon miktarı gözenekli yapılı kalça protezi kullanıldığında dolu malzeme ile yapılan kalça protezi analizine göre artmaktadır. Birinci modelde oluşan toplam deformasyon miktarı dolu malzeme ile yapılan analizde $\sim 8,1 \mathrm{E}-4 \mathrm{~mm}$ iken gözenekli yapı ile yapılan analizde bu değer $\sim 8,71 \mathrm{E}-4$ $\mathrm{mm}$ olmuştur. Malzeme yoğunluğuna bağlı olarak bu değer 8,33E-4 mm'ye kadar düşmüştür ve tüm iyileşme haftalarına göre benzer sonuçlar elde edilmiştir. İkinci modele bakıldığında, deformasyon miktarı $\sim 8,1 \mathrm{E}-4$ $\mathrm{mm}$ değerinden $\sim 8,47 \mathrm{E}-4 \mathrm{~mm}$ değerine artmıştır. İyileşme haftalarına göre bu değer 8,26E-4 mm değerine kadar bir düşüş göstermektedir.

\section{Sonuç ve Tartışma}

İki parçadan oluşan ve alt parçası gözenekli yapıdan tasarlanan kalça protezinin uyluk kemiği üzerindeki analizlerinden elde edilen sonuçlara göre, gözenekli yapıdan üretilen kalça protezleri uyluk kemiğinde ve kalça protezinde daha düşük gerilmeler oluşturmaktadırlar. Çalışmadan elde edilen sonuçlar maddeler halinde aşağıda verilmiştir.

Efektif elastisite modülü gözenekli yapılarda geometriye bağlı olarak yoğunluğun düşmesi ile düşmektedir.

- Gözenekli yapıdan üretilen kalça protezleri kullanıldığında kalça protezinin alt ve üst parçasında dolu malzeme kullanılmasına göre daha düşük gerilmeler oluşmaktadır.

- $\quad$ İki parçadan oluşan kalça protezinin alt parçasının gözenekli yapıdan üretilmesi durumunda, uyluk kemiğinde daha düşük gerilmeler oluşmaktadır.

Sonuçlara bakıldığında, 1. Modelin $35 \mu \mathrm{m}$ delik çaplı gözenekli yapısı ile yapılan analizlerden elde edilen sonuçlara göre, kalça protezi üst ve alt parçası ayrıca uyluk 
kemiğinde oluşan gerilme değerleri düşmüştür. Fakat toplam deplasman değerinde $7 \mathrm{E}-5 \mathrm{~mm}$ değerinde bir artış görülmektedir ki çok düşük bir değer olduğu için kabul edilebilir seviyededir. Bu sebepten dolayı yapılan analizler sonucunda 1.modelin $35 \mu \mathrm{m}$ delik çapına sahip olan gözenekli yapı tasarlanıp analiz edilmiş modeller içerisinde optimum model olarak seçilmiştir.

\section{Kaynaklar}

Abreu, M.E., Viegas, V.N., Ibrahim, D. 2009. Treatment of comminuted mandibular fractures: a critical review, Medicina Oral Patologia Oral y Cirugia Bucal, 14 (5), 247-251.

Ali, D., Sen, S. 2017. Finite element analysis of mechanical behavior, permeability and fluid induced wall shear stress of high porosity scaffolds with gyroid and lattice-based architectures, Journal of the Mechanical Behavior of Biomedical Materials, 75, 262-270.

Balazic, M., Kopac, J., Jackson, M.J., Ahmed, W. 2007. Review: titanium and titanium alloy applications in medicine, International Journal of Nano and Biomaterials, 1 (1), 3-34.

Bilgen, Ö.F. 2011. Kalça Protezlerinde Malzeme ve Tasarım Özellikleri, Türkiye Ortopedi ve Travmatoloji Birliği Derneği Dergisi. 146-156

Boyer, R. 1996. An overview on the use of titanium in the aerospace industry, Materials Science and Engineering: A, 213 (1-2), 103-114.

Bram, M., Stiller, C., Buchkremer, H.P., Stover, D., Baur, H. 2001. High purity titanium, stainless steel and superalloy parts, Advance Engineering Materials, 2, 196-199.

Canpolat, C. 2010. Sinüzoidal Formda Kalça Protezinin Geliştirilmesi ve Sonlu
Elemanlar Yöntemi ile Analizi, Yüksek Lisans Tezi, Gebze Yüksek Teknoloji Enstitüsü.

Entezari, A., Fang, J., Sue, A., Zhang, Z., Swain, M.V., Li, Q. 2016. Yielding behaviors of polymeric scaffolds with implications to tissue engineering, Materials Letters, 184, 108-111.

Ferrero, J. 2005. Candidate materials for highstrength fastener applications in both the aerospace and automotive industries, Journal of materials engineering and performance, 14 (6), 691-696.

Güden, M., Yıldırım, U. 2015. Gözenekli titanyum yapıların üretimi, mekanik özellikleri ve biyomedikal uygulamaları, DOI: 10.13140/RG.2.1.3499.4008.

Kayabaşı, O. 2011. Probabilistic Approach On The Analysis Of a Kayabaşı_Ekici Type Hip Prosthesis Using Approximate Solution Tecniques, Thesis for The Degree of Doctor of Philosophy in Mechanical Engineering, Marmara University Institute for Graduate Studies in Pure and Applied Sciences.

Luo, D., Rong, Q., Chen, Q. 2016. Finiteelement design and optimization of a three-dimensional tetrahedral porous titanium scaffold for the reconstruction of mandibular defects, Medical Engineering \& Physics, 47, 176-183.

Milijkovic, N.D., Ercegan, G.M., Stulic, R.B., Jandric, Z.B. 2011. Computer Aided Evaluation of Total Hip Prosthesis Stability, Journal for Geometry and Graphics, 2, 141-149.

Naghieh, S., Karamooz Ravari, M.R., Badrossamay, M., Foroozmehr, E., Kadkhodaei, M. 2016. Numerical investigation of the mechanical properties of the additive manufactured 
bone scaffolds fabricated by FDM: The effect of layer penetration and postheating, Journal of the Mechanical Behavior of Biomedical Materials, 59, 241-250.

Giró-Perafita, A., Rabionet, M., Puig, T., Ciurana, J. 2016. Optimization of Poli( $\varepsilon$-caprolactone) Scaffolds Suitable for 3D Cancer Cell Culture, Procedia CIRP, 46, 61-66.

Wang, L., Kang, J., Sun, C., Li, D., Cao, Y., Jin, Z. 2017. Mapping porous microstructures to yield desired mechanical properties for application in 3D printed bone scaffolds and orthopaedic implants, Materials \& Design, 133, 62-68.

Wen, C.E., Mabuchi, M., Yamada, Y., Shimojima, K., Chino, Y., Asahina, T. 2001. Precessing and biocompatible porous $\mathrm{Ti}$ anh $\mathrm{Mg}$, Scripta Materialia, 45, 1147-1153.

Wen, C.E., Yamada, Y., Shimojima, K., Chino, Y., Asahina, T., Mabuchi, M. 2002. 'Processing and mechanical properties of autogenous titanium implant materials", Journal of Materials Science, 13, 397-401.

Wieding, J., Souffrant, R., Mittelmeier, W., Bader R. 2013. Finite element analysis on the biomechanical stability of open porous titanium scaffolds for large segmental bone defects under physiological load conditions, Medical Engineering \& Physics, 422-432. 